\title{
Barreras para el acceso al contenido de las webs de universidades españolas
}

\section{Juan Carlos García Gómez}

Departamento de Información y Documentación, Universidad de Murcia.

\section{Resumen}

Revisión y análisis de los sitios web de las universidades españolas a partir de 26 indicadores de malas prácticas en la creación de sitios web. El estudio utiliza datos recopilados en 2006 y en 2009 y muestra la evolución en el diseño en ese intervalo de tiempo, en el que se ha producido un reducción en torno al 10\% de la tasa de errores de diseño. Los dos errores más frecuentes detectados son un excesivo tiempo de descarga de las páginas de inicio y una mala gestión de enlaces de hipertexto. La universidad a la que menos errores se le detectó fue la de Mondragón y a la que más la de Vigo, siendo la UCAM la que más ha mejorado su diseño desde 2006.

Palabras clave: Universidades españolas, usabilidad, accesibilidad, diseño web, evaluación heurística.

\begin{abstract}
Review and analysis of the web sites of the Spanish universities using 26 indicators of bad practices in the creation of web sites. This study uses information compiled in 2006 and in 2009 and it shows the evolution of their design within this period of time. There has been a decrease of around $10 \%$ of the design errors rate. The two most frequent mistakes are the excessive time of download of the starting pages and a bad management of the hypertext links. Mondragón is the university with fewer mistakes spotted and Vigo is the one with more errors, being the UCAM the one that has improved its design the most since 2006.
\end{abstract}

Keywords: Spanish universities, usability, accesibility, web design, heuristic evaluation. 


\section{Introducción}

Una de las razones que nos motivó para acometer este estudio es la existencia de leyes que impelen a las administraciones públicas a preocuparse de que sus sitios web cumplan criterios de Accesibilidad. Así, por ejemplo, tanto la denominada LSSI (Ley 34/2002, de 11 de julio, de Servicios de la Sociedad de la Información y de Comercio Electrónico (BOE de 12 de julio de 2002)) y su posterior desarrollo a través del Real Decreto 1494/2007, de 12 de noviembre, por el que se aprueba el Reglamento sobre las condiciones básicas para el acceso de las personas con discapacidad a las tecnologías, productos y servicios relacionados con la sociedad de la información y medios de comunicación social, como la Ley 11/2007, de 22 de junio, de acceso electrónico de los ciudadanos a los Servicios Públicos regulan esta cuestión, por poner unos ejemplos. Sin embargo, este estudio no se centra de forma exclusiva ni exhaustiva en cuestiones de accesibilidad, pues abarca diversas áreas de la interacción entre personas y sitios webs de universidades.

El hecho de que la LSSI entrara en vigor en 2006 y que este estudio abarque datos recogidos en 2006, apenas unos meses después de la entrada en vigor de esta ley, y también de 2009, nos permite hacer una pequeña aproximación a la evolución y caminos que han tomado las diversas universidades desde entonces en lo que a rediseño de sus sitios web o en cuanto a tener en cuenta o no la ley en dicho rediseño se refiere.

La mayoría de indicadores utilizados en este trabajo están recogidos directamente de los principales trabajos sobre usabilidad y accesibilidad, buena parte de ellos generados por Jakob Nielsen (Nielsen, 2000 ; Nielsen y Tahir, 2002 ; Nielsen y Loranger, 2006, etc.). Otros indicadores, en cambio, han sido elegidos ad hoc para este estudio, teniendo en cuenta nuestra experiencia previa en el contacto diario con las webs universitarias, lo que nos permitió formular a priori una serie de posibles y recurrentes errores en la creación de sitios web universitarios.

\section{Objetivos}

El objetivo principal de este trabajo es detectar algunos de los problemas recurrentes en el diseño de sitios web de universidades españolas que puedan perjudicar al usuario en su intento de acceder a los contenidos de esos sitios web. No abordamos sólo los problemas que pueden afectar en general a cualquier página web, sino también a algunos que se circunscriben de forma muy específica al ámbito de las webs universitarias.

El hecho de que las universidades hayan sido tradicionalmente instituciones punteras en innovación y aplicación de técnicas y tecnologías emergentes hace que estudiar la forma en la que éstas ofrecen su información en la web pueda ser una interesante visión no sólo de su forma de gestionar los sitios web en la actualidad, sino un anticipo del futuro inmediato en otros sectores menos innovadores. Es importante precisar que este estudio tampoco pretende ser exhaustivo a la hora de recoger información útil para detectar todas las posibles barreras de acceso al contenido de las webs de universidades españolas. Para lograr un buen estudio sobre la calidad de este colectivo sería preciso realizar un buen análisis de Accesibilidad de ellos, en la línea de los que viene realizando Discapnet en los últimos años (Discapnet, 2004; Discapnet, 2006), así como de los contenidos propiamente dichos, como se hace en el "Ranking cibermétrico de las web de Universidades Españolas”, publicado en la web webometrics.info, desarrollado por el grupo de trabajo del CINDOC InternetLab (LabInternet, 2006). También es 
interesante que este tipo de estudios entren en aspectos como la ubicuidad y visibilidad (Martínez Méndez, 2008).

Otro aspecto importante que precisaría analizar un buen estudio de este tipo sería la interfaz del sitio web y la forma de distribuir su superficie, cuestión que abordó el grupo GRIHO (Grup de Recerca en Interacció Persona Ordinador i Integració de Dades) a través de su proyecto USABAIPO, que en el año 2005 publicó los resultados de un estudio que analizaba las páginas de inicio de 69 universidades españolas. Este trabajo inspeccionaba el cumplimiento de estándares en los portales de las universidades, el análisis de las zonas de la interfaz del usuario y en el desarrollo de evaluaciones heurísticas (González et. al., 2008), utilizando para la mayoría de los indicadores las recomendaciones de Nielsen y Tahir (2002).

Intentando no repetir uno de estos estudios decidimos centrarnos sobre todo en cuestiones que, dentro del punto de vista de la usabilidad de sitios web, no fueran abordadas directamente en estos estudios, o bien analizarlas desde un punto de vista ligeramente distinto. Así, finalmente nos hemos centrado sobre todo en los aspectos de la interfaz que más tienen que ver con la interacción y la experiencia de usuario más directa, procurando que fueran cuestiones con un alto nivel de influencia en la percepción de la interacción por parte del usuario. Estos indicadores, por tanto, responderían sobre todo a cuestiones de carácter humano, dentro de lo que podría denominarse ‘dimensión sensorial'.

\section{Metodología}

Para la realización de este estudio realizamos una evaluación heurística con la que se revisaron 26 indicadores. Esos indicadores los revisamos en dos tandas, la primera recogida de datos la realizamos en el año 2006 sobre las 73 universidades españolas censadas entonces. Tres años más tarde realizamos una segunda recogida de datos, sobre las 76 universidades españolas detectadas en 2009. Concretamente, la primera serie de datos se registró durante el mes de septiembre de 2006 y la segunda en el mes de septiembre de 2009. La recogida de datos se realizó a partir de la revisión personal de cada uno de esos sitios web, a partir de la cual otorgamos valores a cada uno de los indicadores, los cuales se podrían agrupar en cuatro apartados:

1. Criterio político en el diseño. Se trata de reflejar factores y decisiones de los responsables de una universidad que, sin tener que ver directamente con el diseño, terminan por convertirse en problemas al acceso a la información de las páginas.

2. Legibilidad. Aspectos que influyen en la facilidad de lectura de los textos.

3. Diseño. Cuestiones relacionadas con el diseño propiamente dicho. Modo en el que se muestra la interfaz y los problemas que ello puede ocasionar para la transmisión de información.

4. Ayuda al acceso a la información. Las webs universitarias suelen ser sitios muy grandes, con lo que resulta vital la utilización de herramientas de ayuda al acceso a la información.

En concreto, estos son los 26 indicadores y los enlaces a los detalles sobre cada uno de ellos: 


\subsection{Criterio político en el diseño:}

1. Organizar según el organigrama jerárquico. En algunas universidades se realiza una ordenación de los contenidos no en función de clasificaciones temáticas que puedan ser útiles o entendibles por los usuarios, sino basadas en el organigrama jerárquico de la institución, o la Relación de Puestos de Trabajo. En muchas ocasiones prima el deseo de los altos directivos por controlar incluso la información que se ofrece en la web sin tener formación ni experiencia en ese aspecto. No es fácil detectar inequívocamente cuándo se sigue esta mala práctica. En el contexto de las webs de universidades un pequeño indicio para detectarla podría ser plantear la cuestión: “¿Existe un enlace específico para “Centros y Facultades” o “Facultades y Departamentos”?. Aunque la información sobre centros, facultades y departamentos es fundamental en una web universitaria, no es normal que exista un Vicerrectorado de Centros y Departamentos, de modo que si no existe una categoría de ese tipo en la página principal de una web universitaria es probable que ésta se haya organizado sobre todo en función de la estructura jerárquica.

2. Fragmentación del sitio (diferentes unidades con diferentes webs). Ofrecer un diseño homogéneo en todo un mismo sitio web contribuye a que el usuario tenga claro en todo momento que permanece en el mismo sitio. Para lograr esa homogeneidad no hace falta que las páginas sean prácticamente idénticas, basta con que se repitan una serie de patrones comunes en todas las páginas secundarias, como puede ser la presencia de una misma barra de navegación o encabezado y el logotipo de la universidad, mantener la misma paleta de colores, etc. Sin embargo, algunas universidades, en virtud de la potestad de las distintas unidades que la componen de tener un algo grado de autogestión, permiten que cada unidad desarrolle desde cero su propia página web si así lo desea, empleando para ello las herramientas, criterios y diseños que consideran oportuno, rompiendo así la homogeneidad visual y estructural deseable en una web universitaria. Se ha penalizado en este estudio a las universidades cuyo diseño es heterogéneo, y difiere según la parte de la web en la que se esté.

3. "Saludo del Rector". Una web universitaria ha de ingeniárselas para organizar adecuadamente cantidades ingentes de información. El espacio en la página principal es muy valioso y ha de emplearse en los contenidos más importantes de la universidad, que han de estar muy bien seleccionados y clasificados en la página de inicio. Sin embargo, el saludo del rector o presentación similar parece claro que no está entre esos contenidos más importantes, aunque en muchas universidades aparece éste en los lugares privilegiados que deberían dedicarse a cuestiones como estudios, centros, etc. No queremos decir que no deba existir una página de este tipo en una web universitaria, sino que un enlace en la página principal no es su lugar idóneo, pues no sólo no es una página de interés para los usuarios, sino que en el mejor de los casos será visitada una única vez por éstos. Se ha penalizado a aquellas webs que contenían una presentación del rector o similar en la página principal o a un clic de distancia.

4. Webs bilingües y páginas intermedias. Tanto este indicador como el siguiente están orientados casi exclusivamente a las páginas de universidades ubicadas en comunidades autónomas con lenguas cooficiales. Según se afirma en (Nielsen y Tahir, 2002), (Nielsen, 2004) y (Nielsen y Loranger, 2006), y en buena medida apoya el sentido común, crear una página intermedia sólo para que el usuario elija en qué idioma quiere interactuar es hacerle perder el tiempo. Lo ideal es decidir cuál es el idioma del público mayoritario del sitio y, a partir de ello, crear 
la página directamente en ese idioma, situando bien visibles e identificables en la página principal los enlaces para el cambio de idioma. En muchos casos cuando se opta por crear una página intermedia sólo para elegir idioma esa decisión se toma no por funcionalidad sino por cuestiones relacionadas con la corrección política, ante la posibilidad de disgustar a un colectivo de ciudadanos hipersensibles con el tema del idioma cooficial. En este indicador se ha penalizado a las universidades que tienen una página intermedia sólo para la elección del idioma.

5. Webs 'unilingües'. El caso inverso también tiene cabida en el conjunto de webs de universidades con lengua cooficial, dándose el caso de universidades ubicadas en comunidades autónomas con lengua cooficial que crean la página en sólo uno de los dos idiomas o que esconden tanto el enlace a la versión en el otro idioma que en la práctica la inutilizan. Se ha penalizado a aquellas páginas que, teniendo que estar en más de un idioma, sólo se visualizan, en la práctica, en uno de ellos.

6. Información no relevante en la principal. Cada píxel de espacio en la página principal tiene un gran valor. Por ello en esa página sólo debe aparecer información relevante. En ocasiones algunas universidades ubican en el privilegiado espacio de la página principal informaciones de carácter claramente secundario, cuya presencia obedece más a un deseo expreso de los altos directivos que a una gestión de información honesta, coordinada y equilibrada. Se penaliza en relación a este indicador a las páginas que ofrecen en su página de inicio información poco relevante.

7. Regalar/vender PageRank a Universia. Desde hace unos años Universia solicita a las universidades españolas que coloquen un enlace a este portal desde sus páginas de inicio. Lo que pretende Universia con esta práctica es, fundamentalmente, subir su PageRank a costa de las universidades que le enlazan, logrando incluso aparecer antes en Google que la propia universidad en cuestión. El intercambio de enlaces que pide Universia para ellos no es de la forma 1x1, sino de la forma 1xn. Es decir, el intercambio de enlaces se lo pide a todas las universidades, con lo que Universia recibe centenares de enlaces desde universidades pero sólo aporta a éstas un único enlace, y nunca desde su página principal. Además, el PageRank de las universidades españolas no baja del 6 (suele estar en el 7-8), con lo que cada enlace recibido desde la página principal de una universidad es muy valioso en términos SEO (Optimización para motores de búsqueda) y para el contenido relacionado con la educación superior. La consecuencia de esta práctica es que con frecuencia cuando el usuario busca contenidos característicos de las universidades españolas tiende a encontrar en Google mejor posicionados los contenidos que sobre éstas universidades alberga el portal de Universia que los de la propia universidad, con lo que gracias a esta engañosa política de intercambio de enlaces Universia logra un PageRank superior a las universidades españolas y, por tanto, mejor posicionamiento en buscadores que aquellas. Este intercambio de enlaces está expresa o tácitamente incluido en los acuerdos que Universia realiza con las universidades, pero tenemos serias dudas de que los responsables de las universidades tengan clara la trascendencia que para su institución docente supone este intercambio desigual que, en realidad, le hace perder visibilidad a su universidad en Internet, cediéndosela a Universia. En este indicador se ha penalizado a las universidades que tuvieran un enlace a Universia en su página de inicio. 


\subsection{Legibilidad:}

8. Abusar del lenguaje administrativo. Los sitios web de las universidades suelen contener muchas normativas, resoluciones y textos oficiales o legales. En ocasiones, estos textos suelen estar redactados con un lenguaje innecesariamente árido y complejo, molesto para el usuario medio. No obstante, no dejan de ser documentos oficiales que no se pueden manipular para ser difundidos en la web. Sin embargo, el hecho de que una web contenga muchos textos legales o normativas no justifica que el resto de textos, los informativos relativos a ellos, creados ad hoc para la web por los gestores del sitio, se redacten imitando ese artificioso e incómodo lenguaje administrativo tan poco clarificador (Price y Price, 2002; Nielsen, y Morkes, J., 1997). Este indicador ha sido uno de los más complejos de medir de forma objetiva, al no existir una metodología viable y fácil de aplicar a este aspecto. Elegimos como referencia las páginas relacionadas con los procesos de acceso y matriculación, diferenciando entre lo que son los enlaces a las leyes y normas propiamente dichos de los textos de las páginas de acceso a estos, penalizando el abuso del lenguaje administrativo, fundamentalmente el uso excesivo de la voz pasiva.

9. Documentos poco escaneables. Los usuarios no leen los textos de las páginas de forma secuencial, normalmente escanean la página con la vista, en un recorrido en forma de $\mathrm{Z}$ o de $\mathrm{F}$ (alt64, 2005). Para crear páginas que le faciliten el trabajo al ojo humano se deben emplear párrafos cortos, renglones de ancho medio (60$90 \mathrm{cpl}$ ), listas, negrita, encabezados, tablas de resumen, etc. (Price y Price, 2002; Nielsen, y Morkes, J., 1997). Se ha penalizado con este indicador a aquellas universidades que no respetan la mayoría de estas recomendaciones para la gestión de textos y generan textos con baja legibilidad.

10. Contenido con poco ‘aire' / Colapso informacional (saturación de contenido). / No dejar respirar a la página. La página principal es la más importante de una página web. El espacio en blanco resulta vital para contribuir a la visibilidad de los elementos y su comprensión. Por tanto, saturar la página principal de contenidos propicia que éstos, o buena parte de ellos, resulten invisibles al lector, que se ve desbordado, sobreestimulado, y termina por no poder rastrear fácilmente sus contenidos. Es imposible destacarlo todo. Si se cae en el error de intentar mostrar todos los contenidos de color diferente unos de otros se obtendrá una amalgama de colores difícil de asimilar. En una página web ocupar todo el espacio en blanco disponible, no es aprovechar el espacio, sino precisamente lo contrario. Evidentemente, tampoco es conveniente lo contrario, es decir, hacer que prácticamente todo sea espacio en blanco. El problema, por tanto, es determinar la cantidad exacta de espacio en blanco que debe tener una página de inicio para estar en los márgenes correctos. Según Nielsen y Thair (2002) el espacio sin utilizar de una página de inicio debería situarse en torno al $25 \%$, y el empleado como mero relleno en el 6\%. En este indicador hemos penalizado a las páginas que tienden a saturar de contenidos el espacio disponible, dificultando así la fácil percepción de los contenidos disponibles.

\subsection{Diseño:}

11. Pop ups. Aunque se trata de una mala práctica que ya debería estar totalmente erradicada, aún es posible detectar casos en los que se abren ventanas emergentes (pop ups) no solicitadas por el usuario. Uno de los problemas que plantea una ventana emergente no solicitada estriba en que el usuario puede desconcertarse ante ella, puede despistarse si utiliza un navegador sólo texto o 
pierde el foco en un navegador vía voz. Pero aún es más problemático desde que, hace relativamente poco tiempo, los principales navegadores incorporan por defecto en sus últimas versiones bloqueadores de pop ups, lo que hace que éstos puedan pasar totalmente desapercibidos para el usuario. Así, colocar en una ventana emergente información importante es un problema para nada menor, pues hay una alta probabilidad de que ésta no llegue a la mayoría de usuarios. Hemos penalizado a las universidades que emplean estas ventanas emergentes.

12. Abuso de menús desplegables. Un menú desplegable que aún no se ha desplegado no muestra información alguna. Si, además, no queda claro a simple vista que se trata de un menú desplegable no sólo no se estará mostrando la información en ese momento, sino que cabe la posibilidad de que muchos usuarios se queden sin ver nunca los enlaces del menú desplegable, simplemente porque no acertaron a comprender que debían pinchar o aproximar el ratón para que se pudiera ver el contenido de éste. Muchos de los usuarios de Internet llevan años usando el ratón y no padecen problemas motrices en sus manos, pero también hay usuarios que no tienen experiencia en el manejo del ratón y para quienes utilizar un menú desplegable es una actividad muy compleja. Se ha penalizado a las webs que incluyen menús desplegables que se despliegan al situar sobre ellos el cursor del ratón.

13. Olvidar la finalidad de servicio (abuso de color, flash y multimedia). La web en general, y especialmente una web universitaria, es un servicio de información, y en la mayor parte de los casos, hablamos incluso de un servicio público o para el público. Es un objetivo loable el buscar que sea agradable navegar por un sitio web, pero es muy discutible que sea agradable para el usuario visualizar una película multimedia cada vez como paso previo a entrar a un sitio web. No hay que confundir tampoco el crear un entorno bello y agradable para los ojos y para la interacción con el abuso de la utilización de colores, películas flash, elementos en continuo movimiento, etc. El objetivo de una página web universitaria debería ser informar. El diseño gráfico y la multimedia deben estar al servicio de la información y han de mejorar dicho proceso de información y la experiencia de usuario en general, no entorpecer el acceso a la información. Se ha penalizado a las páginas que tienden a abusar del uso de colores y presentaciones multimedia que distraen de la información principal.

14. Transmitir información sólo con imágenes. No se debe emplear imágenes para mostrar texto, por la sencilla razón de que no todo el mundo puede verlas, en unos casos porque se trata de personas con discapacidad visual, en otros por motivos técnicos, tales como la configuración del ordenador del usuario, una conexión lenta, que el propio usuario desactiva las imágenes o porque utiliza un navegador sólo texto. Por otro lado, si se muestran imágenes que tienen una razón de ser ha de proveerse una alternativa textual para ellas. Si se trata de una imagen meramente decorativa debe mostrarse desde la CSS. En ocasiones el diseñador opta por utilizar una imagen donde debería aparecer un texto porque desea que la página se vea del modo exacto a como él pretende, lo que es imposible de conseguir usando texto, pues éste se muestra de múltiples formas dependiendo de la configuración del navegador del usuario, quien incluso puede modificar su aspecto si así lo desea. En Internet las cosas no deben mostrarse igual en todas las pantallas, sino que deben verse bien en todos los dispositivos, que no es lo mismo. Además, utilizar una imagen donde debería aparecer un texto hace que la descarga de la página sea más lenta, pues siempre ocupará más una imagen que un texto. Otro argumento de peso es que Google es 'ciego'. Es 
decir, no puede ver las imágenes, sólo el texto alternativo de éstas y el texto propiamente dicho. Si Google, es decir, los buscadores en general, no indiza los contenidos de una página esa página tenderá a ser invisible en la red. Por tanto, hemos penalizado en este indicador a aquellas páginas que mostraban mediante imágenes información que debería mostrarse en formato textual, o a aquellas que no utilizan las etiquetas ALT para la descripción de las imágenes.

15. Tiempos de descarga excesivos (más de 100/150 kb). Diversos estudios muestran que el límite de tiempo para mantener la atención del usuario en una interacción en la web es un máximo de 10 segundos (Nielsen, 2000), momento a partir del cual si no se ha descargado la página el usuario agota su paciencia y desiste. Utilizando como referencia la velocidad media de descarga en equipos con conexiones medias o lentas y que en circunstancias reales la velocidad de descarga no suele sobrepasar la mitad de su capacidad teórica, podríamos estimar la transferencia real para una conexión de $256 \mathrm{~kb} / \mathrm{s}$ en unos $16 \mathrm{~kb} / \mathrm{s}$, lo que hace que para un tiempo máximo de espera de 10 segundos el peso máximo para que una página se descargue totalmente se sitúa en torno a $150 \mathrm{~kb}$. Para la recogida de datos de 2006 esa barrera la situamos en 100 kb. Así, en este indicador hemos penalizado a aquellas páginas de inicio cuyo peso total excediera los $100 \mathrm{~kb}$ en 2006 y los $150 \mathrm{~kb}$ en 2009.

16. Mala gestión de enlaces (color de enlaces visitados). La web siempre ha tenido unos cuántos signos distintivos que ayudaban al usuario en su navegación por la red. Uno de ellos era mostrar los enlaces en color azul y subrayado y cuando se usaban pasaban a tener color morado. Así, además de distinguir lo que era un enlace de lo que no lo era se diferenciaba fácilmente entre los que uno ya había visitado y los que no. Es recomendable que los enlaces se muestren con aspecto diferenciado del texto, distinto a su vez del aspecto de los enlaces ya visitados. En este indicador penalizamos las páginas que no muestran los enlaces de modo diferenciado y no diferencien el aspecto entre los visitados y no visitados.

17. Uso de frames. Los marcos o frames son áreas dentro de una página web que a su vez contienen otra página web. Uno de los problemas que generan los marcos es que esconden la url real de la página que el usuario está consultando en ese momento, pues siempre aparece la misma url en el cajetín de localización, aunque las páginas en realidad van cambiando dentro de los marcos, con lo que el usuario puede tener problemas para percatarse de ello. Lo anterior dificulta también ofrecer enlaces con dicha página, pues el enlace que tenderá a tomar como referencia el usuario será el de la página contenedora de marcos, pero le costará identificar la url de una página concreta que aparezca en uno de esos marcos. También puede ser molesto para los usuarios que algunos contenidos se corten bruscamente en un lugar cualquiera de la página y sea necesario recurrir a una barra de scroll que aparece en mitad de ésta para ver ese fragmento de contenido. Ello, además de desconcertante, puede ser bastante incómodo. Por otro lado, se destruye la estructura lógica del documento. Los marcos delimitan dónde aparece cada contenido pero no marcan qué es cada cosa. Además, los marcos dificultan la visualización en algunos dispositivos especiales. Así, se ha penalizado a los sitios web que utilizaban marcos para mostrar los contenidos.

18. No hacer diseño líquido/No usar renglones optimizados. Este indicador ha sido el único que ha sufrido una modificación importante en su concepción y medición en la toma de datos de 2009 respecto de la de 2006. Hasta el año 2006 aceptamos como adecuado el diseño líquido (el basado en medidas proporcionales o en porcentajes respecto del total del espacio disponible en 
pantalla). Sin embargo, con el crecimiento y diversidad de dispositivos de visualización no es infrecuente la existencia de monitores de altísima resolución, para los que un diseño líquido sin más no sería una solución óptima en cuanto a la visualización y legibilidad de los textos. Así, en la recogida de datos de 2009 el aspecto de maquetación y forma de mostrar los contenidos que tuvimos en cuenta fue más específico, centrándonos en el aspecto clave del diseño: la correcta legibilidad de los textos, con lo que en la recogida de datos de 2009 se tuvo en cuenta si se había realizado un trabajo para la optimización del ancho de los renglones. Aunque los diversos estudios sobre el tema no muestran un acuerdo en una cifra exacta, sí parece claro que en ningún caso deba emplearse renglones de un ancho mayor a los 100 caracteres por renglón (García Gómez, 2005). Así, hemos penalizado aquellas páginas en las que no se haya optimizado el diseño de página para evitar renglones demasiado largos, de más de $100 \mathrm{cpl}$.

19. Diseño epatante pero despistante. Una buena estética es importante para mejorar la experiencia de usuario y para transmitir información no textual (seriedad, dinamismo, profesionalidad, etc.) pero si la estética no se usa como medio sino como fin, se pone en peligro la divulgación de la información que se supone primordial en el sitio web. Este indicador está relacionado también con los estándares de facto, normas no escritas sobre modos de actuar en el diseño web, de modo que salirse de ellos obliga al usuario a un esfuerzo adicional para entender el diseño. La medición de este indicador no resultó fácil, pues no hay metodología capaz de marcar el límite de cuándo un diseño es contraproducente por demasiado espectacular u original, lo que nos llevó a penalizar este aspecto únicamente para páginas en las que no tuviéramos atisbo de duda respecto al abuso en cuanto a búsqueda de espectacularidad y heterodoxia de diseño.

20. No tener claro cuál es la página principal (redirecciones). En ocasiones algunos sitios web realizan una redirección automática. El problema de esta acción estriba en que, por un lado, puede despistar al usuario, pues él tecleó una dirección y termina en otra distinta. También es posible que si el usuario tiene desactivado javascript termine sin poder ver nada en su pantalla. Además, con determinados modos de redirección es muy probable que los robots de buscadores como Google no consigan indexar los contenidos de esa página. En este indicador penalizamos a aquellas páginas en las que tras teclear la url de la universidad aparece en el campo "localización” una url distinta.

21. Falsa Accesibilidad (Ayudas al tipo de letra y contraste). Es interesante que un usuario pueda modificar el tipo de letra, variar el contraste de los elementos de la página y controlar ciertos aspectos relacionados con la accesibilidad de la página. Sin embargo, el lugar apropiado para controlar dicha acción es el navegador web. El que la mayoría de navegadores web no implementen de manera fácil esas funciones no es razón suficiente para que los diseñadores hayan de incluir esas funcionalidades características del navegador en la propia página web (Heilmann, 2006). No obstante, normalmente es un problema menor, pues no se ocupa demasiado espacio en la página y se hace con intención de mejorar la experiencia de usuario. En otros casos no está tan clara la presencia de estos elementos, especialmente cuando no se ha realizado un trabajo de mejora de la Accesibilidad de la página pero pese a ello se incorporan, más por estar de moda o de aparentar una accesibilidad que realmente no tienen que a un verdadero interés en ayudar al usuario. Hemos penalizado a aquellas páginas que incorporan estas supuestas ayudas. 


\subsection{Ayuda al acceso a la información:}

22. Buscadores perdidos o inexistentes. Las web universitarias son, por lo general, muy grandes. Estos sitios web suelen tener bastantes miles de páginas activas. Además de una buena Arquitectura de la Información, un buen buscador es fundamental para facilitar el acceso a la información, especialmente la situada en los niveles más profundos del sitio. No tener buscador o esconderlo en las páginas secundarias dificulta el acceso a la información. El buscador debería estar en la página principal, bien visible y, a ser posible, ubicado arriba a la derecha y con un ancho para teclear de más de 20 caracteres (Nielsen, 2002). Hemos penalizado a aquellas webs que no tenían buscador en su página de inicio, lo tenían ubicado en un lugar poco visible, con un diseño que lo camuflara o le hiciera parecer algo distinto a un buscador.

23. Ausencia de Teléfono y dirección Postal. Pese a que la web está cada vez más extendida como herramienta de comunicación, muchas personas cuando han de hacer una gestión que consideran "importante" (tal como elegir universidad o informarse sobre algún tema de la matrícula) aún prefiere usar el teléfono o desplazarse personalmente. Por ello, la presencia de un número de teléfono y de una dirección postal tiende a tranquilizar y dar confianza al usuario al hacerle saber que siempre podrá contar con esa vía de contacto si falla la telemática. No ofrecer en la página principal un número de teléfono y una dirección postal con la que contactar o a la que dirigirse es un fallo importante. No es suficiente con que información esté presente en alguna parte de la web, sino que ha de estar en la página principal, de forma que al usuario no le lleve mucho más de un par de segundos localizar sendos datos. Hemos penalizado a las páginas que no tenían información de contacto telefónico o ubicación física en su página de inicio.

24. Ausencia de Rastro de migas de pan o similar. Las web universitarias suelen tener una estructura de contenidos muy profunda y compleja, con lo que necesitan ayudas contextuales a la navegación. En muchos casos los usuarios acceden a una página interior de una web universitaria directamente desde un buscador. Así, resulta muy importante poder contar con una ayuda a la navegación del tipo rastro de migas de pan. El rastro de migas de pan es una de las ayudas a la navegación más útiles y fáciles de entender por el usuario, ya que le facilita ubicarse en la jerarquía del web, brindándole enlaces directos a cada uno de los niveles jerárquicos superiores. Hemos penalizado en este indicador a las páginas web que no incluyeran esta ayuda a la navegación o una similar.

25. Ausencia de RSS. RSS, Really Simple Syndication (Sindicación realmente simple), es un formato basado en el lenguaje XML que permite el acceso a contenidos mediante programas lectores de RSS. Así, es posible tener constancia de la actualización de gran cantidad de páginas directamente en el escritorio, cliente de correo o a través de la Web, al poco tiempo de ser actualizadas por su autor. No utilizar RSS en las web de las universidades españolas priva a los usuarios de poder informarse de forma inmediata de los nuevos contenidos de un modo muy simple y cómodo para el usuario y mediante una tecnología suficientemente sencilla y madura como para que su presencia en una página web que se actualiza frecuentemente como es una web de universidad sea muy importante. Hemos penalizado a aquellas páginas que no incluyen algún tipo de servicio de sindicación de noticias con RSS o tecnología similar.

26. No diferenciar la intranet del resto. Es normal que en las universidades existan contenidos o áreas cuyo acceso deba estar limitado únicamente a determinados miembros de esa comunidad (Intranet o Extranet). No obstante, consideramos 
una mala práctica el no dejar bien claro al usuario de antemano qué parte de la web está restringida. Deben separarse los contenidos que son exclusivos para miembros de la universidad en cuestión, que requieren acceso identificado, del resto. Mezclar unos enlaces con otros puede producir molestias y desconcierto en los no miembros. Hemos penalizado con este indicador a las universidades que mezclan enlaces exclusivos de intranet (que requieren una identificación previa) con el resto y lo hacen sin dejar claro su condición de área intranet.

\section{Resultados}

Los resultados muestran que las universidades españolas incurren en 2009 en una media del 28\% de los errores revisados en este estudio. Este porcentaje era del 37\% en 2006, lo que indica que en estos tres años las universidades han superado el $9 \%$ de esos fallos.

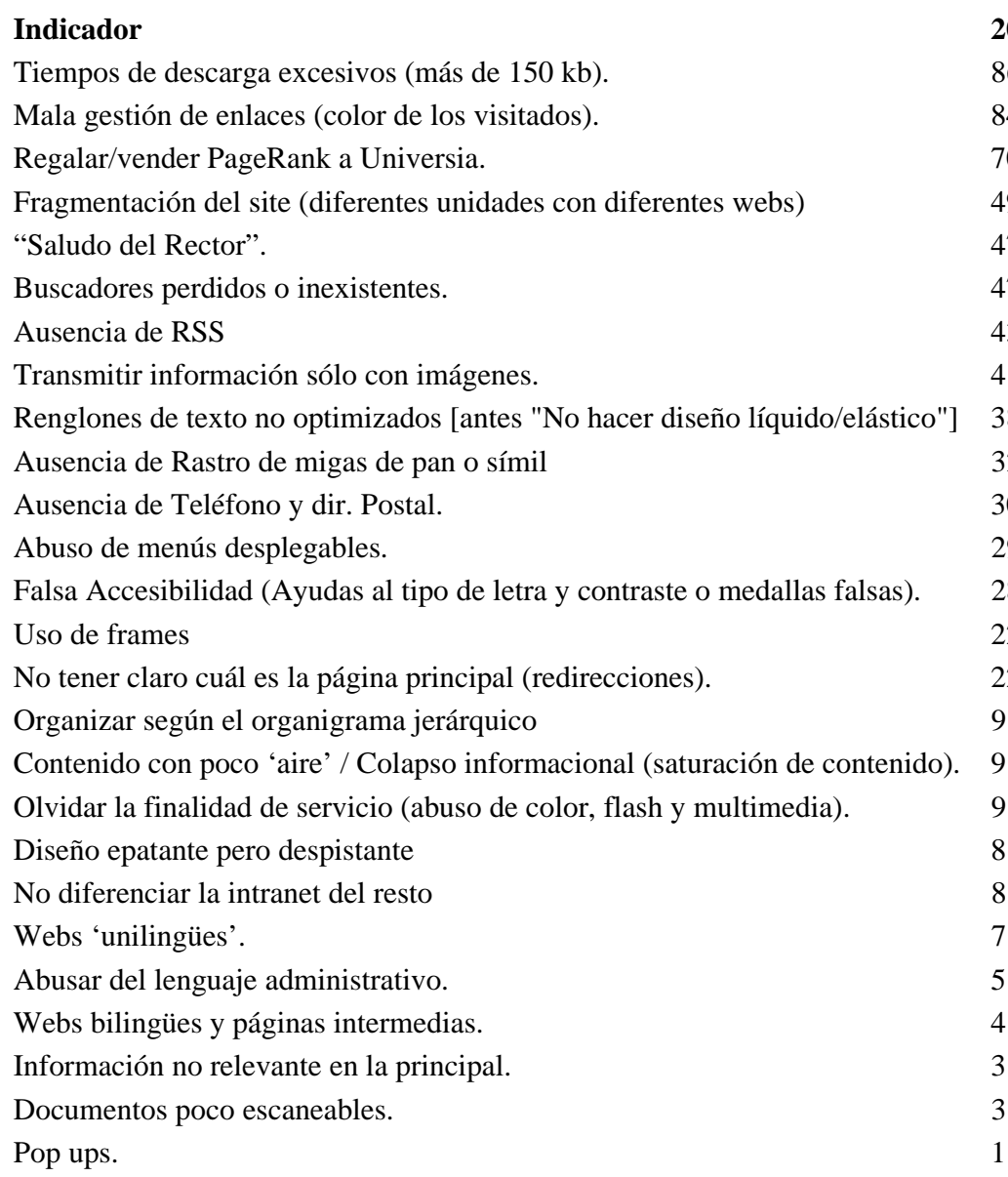

\begin{tabular}{|c|c|c|}
\hline $2009 \%$ & $2006 \%$ & Dif 06 - 09 \\
\hline 86 & 82 & 3 \\
\hline 84 & 84 & 1 \\
\hline 70 & 71 & -1 \\
\hline 49 & 59 & -10 \\
\hline 47 & 30 & 17 \\
\hline 47 & 53 & -6 \\
\hline 43 & 86 & -43 \\
\hline 41 & 44 & -3 \\
\hline 38 & 85 & -47 \\
\hline 32 & 55 & -23 \\
\hline 30 & 36 & -5 \\
\hline 29 & 37 & -8 \\
\hline 28 & 14 & 14 \\
\hline 22 & 33 & -11 \\
\hline 22 & 25 & -2 \\
\hline 9 & 19 & -10 \\
\hline 9 & 12 & -3 \\
\hline 9 & 14 & -4 \\
\hline 8 & 7 & 1 \\
\hline 8 & 11 & -3 \\
\hline 7 & 7 & 0 \\
\hline 5 & 48 & -43 \\
\hline 4 & 8 & -4 \\
\hline 3 & 37 & -34 \\
\hline 3 & 14 & -11 \\
\hline 1 & 4 & -3 \\
\hline 28 & 37 & -9 \\
\hline
\end{tabular}

Tabla I. Malas prácticas y su incidencia en 2006 y 2009

Hay que señalar que en el año 2009 modificamos un indicador de los utilizados en 2006 (“No hacer diseño líquido/elástico") transformándolo en un nuevo indicador ("Renglones de texto no optimizados"), no analizado en 2006 como tal. Este indicador fue descartado en 2009 por la evolución de las prestaciones de los navegadores web, que dejaba carente de sentido su observación al incorporar habitualmente el efecto zoom, lo que permite obviar el observar este diseño. Por tanto, la gran disparidad de resultados para este indicador es lógica al no revisarse exactamente el mismo aspecto. Si lo elimináramos del cómputo global, el resultado final no variaría excesivamente, pues para 2009 seguiría siendo un 28\%, para 2006 un 36\% y la diferencia un 8\%. 
Las malas prácticas detectadas aún en más del $50 \%$ de universidades son: tiempos de descarga excesivos (86\%), mala gestión de los enlaces (84\%) y regalar/vender PageRank a Universia (70\%). Estas malas prácticas apenas han variado desde 2006 lo que, unido a su alto grado de incidencia, nos hace pensar que no son consideradas por las propias universidades como errores en realidad. Los problemas que más se han subsanado en estos tres años son: Ausencia de RSS (ha mejorado un 43\%), abusar del lenguaje administrativo (también mejora un 43\%, hasta prácticamente quedar erradicado), colocar información no relevante en la página principal (se reduce un 34\% y también queda casi erradicado) y ausencia de rastro de migas de pan (mejora un 23\%, de forma que ahora más de la mitad de las universidades lo usan). Curiosamente hay indicadores cuyos resultados han empeorado: incluir el saludo del rector es una práctica que se ha incrementado un 17\%, la inclusión de falsas ayudas de accesibilidad (incrementar el tamaño de letra o cambiar contraste de la página) ha incrementado un 14\%. El resto de indicadores, o permanece prácticamente igual o mejora.

\subsection{Diferencias entre universidades públicas y privadas:}

No hay grandes diferencias en las cifras globales entre universidades públicas y privadas, pues el porcentaje de malas prácticas detectadas en las públicas es un $28 \%$ y un $26 \%$ en las privadas.

\begin{tabular}{|c|c|c|}
\hline Indicador & \% Públicas & $\%$ Privadas \\
\hline Organizar según el organigrama jerárquico & 9 & 0 \\
\hline Fragmentación del site (diferentes unidades con diferentes webs) & 49 & 20 \\
\hline “Saludo del Rector”. & 47 & 60 \\
\hline Webs bilingües y páginas intermedias. & 4 & 0 \\
\hline Webs ‘unilingües’. & 7 & 0 \\
\hline Información no relevante en la principal. & 3 & 0 \\
\hline Regalar/vender PageRank a Universia. & 70 & 44 \\
\hline Abusar del lenguaje administrativo. & 5 & 4 \\
\hline Documentos poco escaneables. & 3 & 0 \\
\hline Contenido con poco 'aire' / Colapso informacional (saturación de contenido & & \\
\hline No dejar respirar a la página. & 9 & 0 \\
\hline Pop ups. & 1 & 4 \\
\hline Abuso de menús desplegables. & 29 & 36 \\
\hline Olvidar la finalidad de servicio (abuso de color, flash y multimedia). & 9 & 12 \\
\hline Transmitir información sólo con imágenes. & 41 & 56 \\
\hline Tiempos de descarga excesivos (más de 150 kb). & 86 & 96 \\
\hline Mala gestión de enlaces (color enlaces visitados). & 84 & 92 \\
\hline Uso de frames & 22 & 20 \\
\hline Renglones de texto no optimizados [antes "No hacer diseño líquido/elástico"] & 38 & 36 \\
\hline Diseño epatante pero despistante & 8 & 8 \\
\hline No tener claro cuál es la página principal (redirecciones). & 22 & 32 \\
\hline Falsa Accesibilidad (Ayudas al tipo de letra y contraste o medallas falsas). & 28 & 24 \\
\hline Buscadores perdidos o inexistentes. & 47 & 56 \\
\hline Ausencia de Teléfono y dir. Postal. & 30 & 16 \\
\hline Ausencia de Rastro de migas de pan o símil & 32 & 24 \\
\hline Ausencia de RSS & 43 & 44 \\
\hline No diferenciar la intranet del resto & 8 & 0 \\
\hline Media & 28 & 26 \\
\hline
\end{tabular}

Tabla II. Comparativa entre universidades públicas y privadas

Sí se detectan diferencias significativas, de más del 10\%, en algunos indicadores. Así, prácticamente la mitad de las universidades públicas cometen el error de fragmentar el 
sitio web (hacer diferentes webs para diferentes unidades), mientras que en las universidades privadas este error sólo se comete en el 20\% de ellas.

El saludo del rector es mucho más frecuente en las privadas (60\%) que en las públicas (47\%). Ocurre lo contrario con los enlaces a Universia (el 70\% de las universidades públicas enlaza desde su página de inicio por un $44 \%$ en las privadas). Algo menor es la diferencia en el peso de las páginas de inicio, siendo un $96 \%$ de las universidades privadas cuyas páginas de inicio pesan más de $150 \mathrm{~kb}$, siendo algo menos en las públicas (un 86\%). Es significativa la diferencia de porcentaje de universidades públicas que olvidan dar información de contacto (teléfono y dirección postal) en su página principal, un 30\% en total, frente al 16\% de privadas que cometen este error.

\subsection{Datos por universidades}

En cuanto a los resultados observados por universidades 8 son las universidades en las que se han detectado menos de 5 errores: Mondragón (2), Rovira i Virgili (3), CastillaLa Mancha (4), La Laguna (4), Autónoma de Barcelona (4), Deusto (4), Jaume I (4), Santiago de Compostela (4). Las universidades que peores resultados han cosechado, con más de 10 errores cada una, son: Vigo (18), Miguel Hernández (14), Autónoma de Madrid (13), Rey Juan Carlos (12), Pablo Olavide (11), Cantabria (11). El resto de universidades se sitúan entre los 5 y los 10 errores, distribuidas en: 6 universidades con 5 errores, 18 con 6 errores, 13 con 7 errores, 10 con 8 errores, 9 con 9 errores y 6 con 10 errores.

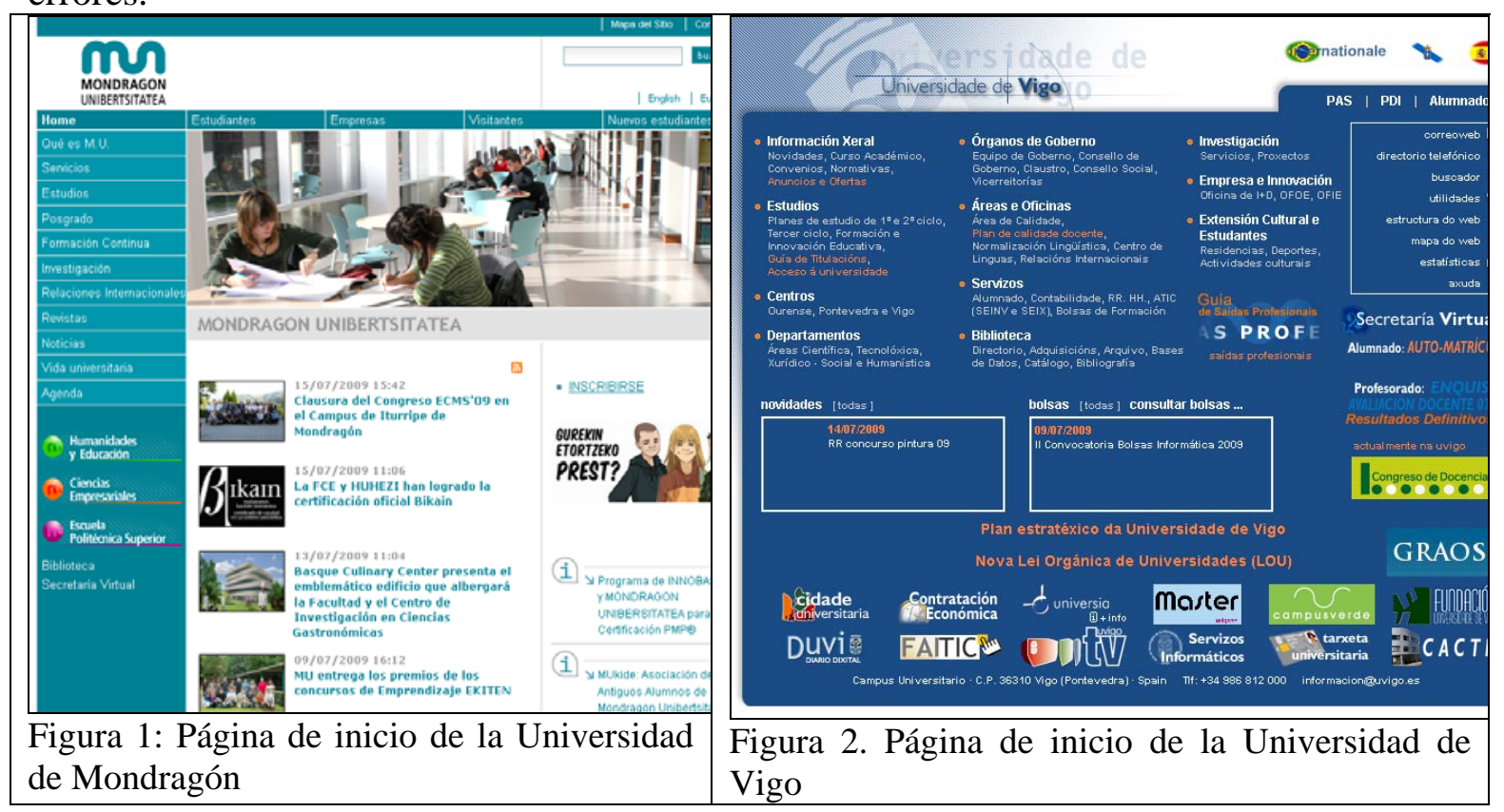

Si consideramos la diferencia entre los valores recogidos en 2006 y los recogidos en 2009 las universidades que más han mejorado en estos tres años son: Católica de Murcia (9 errores menos que en 2006), Castilla La Mancha (8 errores menos), La Laguna (8), Cádiz (8), Internacional de Andalucía (8), Salamanca (8), Rovira i Virgili (7), Almería (7), Autónoma de Barcelona (6), Barcelona (6). Esta mejora de varias universidades proviene en la mayoría de casos del rediseño total de varias de las que en el año 2006 se situaban entre las que peores resultados obtenían, tales como Católica de Murcia, Barcelona, Salamanca, Cádiz, Internacional de Andalucía y Almería, todas ellas con más de 12 errores en 2006 y entre las 10 que más problemas se les detectaron 
entonces. La media de errores detectada en 2006 fue de 9,7, mientras que en 2009 fue de 7,3 .

\begin{tabular}{|c|c|c|c|c|c|c|c|}
\hline Universidad & 2009 & 2006 & dif & Universidad & 2009 & 2006 & dif \\
\hline Mondragón & 2 & 5 & -3 & Alicante & 7 & 8 & -1 \\
\hline Rovira i Virgili & 3 & 10 & -7 & Complutense & 7 & 8 & -1 \\
\hline Castilla-La Mancha & 4 & 12 & -8 & $\begin{array}{l}\text { Pompeu Fabra } \\
\text { Cardenal }\end{array}$ & 7 & 8 & -1 \\
\hline La Laguna & 4 & 12 & -8 & $\begin{array}{l}\text { Herrera CEU } \\
\text { Europea }\end{array}$ & 7 & 8 & -1 \\
\hline Autónoma Barcelona & 4 & 10 & -6 & $\begin{array}{l}\text { Madrid } \\
\text { Pontificia }\end{array}$ & 7 & 8 & -1 \\
\hline Deusto & 4 & 7 & -3 & Comillas & 7 & 8 & -1 \\
\hline Jaume I & 4 & 6 & -2 & Córdoba & 7 & 5 & 2 \\
\hline Santiago & 4 & 5 & -1 & $\begin{array}{l}\text { Lebrija } \\
\text { Politécnica }\end{array}$ & 8 & 12 & -4 \\
\hline $\begin{array}{l}\text { Cádiz } \\
\text { Internacional }\end{array}$ & 5 & 13 & -8 & Valencia & 8 & 11 & -3 \\
\hline $\begin{array}{l}\text { Andalucía } \\
\text { Internacional }\end{array}$ & 5 & 13 & -8 & $\begin{array}{l}\text { Illes Balears } \\
\text { Abat Oliba }\end{array}$ & 8 & 10 & -2 \\
\hline Catalunya & 5 & 9 & -4 & CEU & 8 & 10 & -2 \\
\hline Pontificia Salamanca & 5 & 9 & -4 & Católica Ávila & 8 & 10 & -2 \\
\hline Pública de Navarra & 5 & 8 & -3 & Valencia & 8 & 9 & -1 \\
\hline Francisco Vitoria & 5 & 5 & 0 & Alfonso X & 8 & 8 & 0 \\
\hline Católica Murcia & 6 & 15 & -9 & La Rioja & 8 & 7 & 1 \\
\hline Salamanca & 6 & 14 & -8 & $\begin{array}{l}\text { IE Universidad } \\
\text { Universidad }\end{array}$ & 8 & & \\
\hline Almería & 6 & 13 & -7 & Int. Valenciana & 8 & & \\
\hline Girona & 6 & 11 & -5 & Barcelona & 9 & 15 & -6 \\
\hline Murcia & 6 & 11 & -5 & Huelva & 9 & 11 & -2 \\
\hline Burgos & 6 & 10 & -4 & Zaragoza & 9 & 11 & -2 \\
\hline Granada & 6 & 10 & -4 & Carlos III & 9 & 10 & -1 \\
\hline Católica Valencia & 6 & 10 & -4 & $\begin{array}{l}\text { Extremadura } \\
\text { Int. Menéndez }\end{array}$ & 9 & 10 & -1 \\
\hline Oberta Catalunya & 6 & 10 & -4 & Pelayo & 9 & 10 & -1 \\
\hline San Pablo CEU & 6 & 10 & -4 & A Coruña & 9 & 9 & 0 \\
\hline $\begin{array}{l}\text { Alcalá de Henares } \\
\text { Europea Miguel }\end{array}$ & 6 & 9 & -3 & $\begin{array}{l}\text { Vic } \\
\text { Internacional }\end{array}$ & 9 & 9 & 0 \\
\hline Cervantes & 6 & 9 & -3 & La Rioja & 9 & & \\
\hline Navarra & 6 & 9 & -3 & $\begin{array}{l}\text { Jaén } \\
\text { Politécnica }\end{array}$ & 10 & 12 & -2 \\
\hline $\begin{array}{l}\text { Lleida } \\
\text { Las Palmas de Gran }\end{array}$ & 6 & 8 & -2 & Cartagena & 10 & 10 & 0 \\
\hline Canaria & 6 & 7 & -1 & León & 10 & 9 & 1 \\
\hline Málaga & 6 & 7 & -1 & $\begin{array}{l}\text { Ramón Llull } \\
\text { Camilo José }\end{array}$ & 10 & 9 & 1 \\
\hline $\begin{array}{l}\text { Sevilla } \\
\text { Universidad a }\end{array}$ & 6 & 7 & -1 & $\begin{array}{l}\text { Cela } \\
\text { Politécnica }\end{array}$ & 10 & 7 & 3 \\
\hline Distancia de Madrid & 6 & & & Catalunya & 10 & 6 & 4 \\
\hline País Vasco & 7 & 12 & -5 & Cantabria & 11 & 14 & -3 \\
\hline Valladolid & 7 & 12 & -5 & $\begin{array}{l}\text { Pablo Olavide } \\
\text { Rey Juan }\end{array}$ & 11 & 14 & -3 \\
\hline $\begin{array}{l}\text { Politécnica Madrid } \\
\text { Nacional Educación a }\end{array}$ & 7 & 11 & -4 & $\begin{array}{l}\text { Carlos } \\
\text { Autónoma de }\end{array}$ & 12 & 14 & -2 \\
\hline Distancia & 7 & 10 & -3 & $\begin{array}{l}\text { Madrid } \\
\text { Miguel }\end{array}$ & 13 & 10 & 3 \\
\hline Oviedo & 7 & 9 & -2 & Hernández & 14 & 14 & 0 \\
\hline \multirow[t]{2}{*}{ San Jorge } & 7 & 9 & -2 & Vigo & 18 & 13 & 5 \\
\hline & & & & SEK & & 7 & -7 \\
\hline
\end{tabular}

Tabla III. Evolución de errores por Universidad en el período analizado. 


\section{Conclusiones}

Las universidades españolas en los últimos tres años han mejorado sensiblemente en cuanto a reducción de barreras al acceso a la información de sus webs. Las universidades que más han mejorado en su diseño desde 2006 tienden a ser las universidades que peores resultados mostraban hace tres años. De ese hecho se podría inferir una preocupación por la calidad de sus diseños de aquellas universidades que han realizado rediseños recientemente, pasando algunas de ellas de estar entre las peor situadas a formar parte directamente del grupo de cabeza.

El hecho de que esta gran mejora se haya producido durante el corto período que va desde el 2006 al 2009 podría llevarnos a buscar alguna relación de ésta con la entrada en vigor de la LSSI precisamente en el año de la primera observación. Podríamos pensar, por tanto, que dicha ley está siendo tenida en cuenta, al menos en parte, por las universidades a la hora de hacer sus rediseños, pero que por sí misma no ha logrado que las universidades tomaran medidas para mejorar los diseños de sus páginas web en el momento de la entrada en vigor (1 de enero de 2006), sino que esas mejoras sólo se han introducido cuando con posterioridad han decidido rediseñar sus páginas.

Algunas de las mejoras producidas en estos tres años han venido de la mano de la tecnología, de la proliferación de tecnologías y su progresiva implantación en las universidades. Ése es el caso del uso de RSS o el de tecnologías que permiten la automatización de elementos de ayuda a la navegación como el rastro de migas de pan. Otras mejoras dan la sensación de estar derivadas de una mayor madurez de los responsables de los diseños de páginas web de este tipo, como parece desprenderse de la casi erradicación de la presencia de información poco relevante en las páginas de inicio, de forma similar a como ocurre con el abuso del lenguaje administrativo.

Esta lista de malas prácticas no es cerrada, ni exhaustiva. Sólo son un subconjunto de las posibles, centradas aquí en los factores que podríamos denominar principalmente humanos (o dimensión sensorial). Para una correcta evaluación de la calidad de las páginas web de universidades españolas sería preciso abarcar bastantes más indicadores, relacionados con Accesibilidad, Usabilidad, Arquitectura de la Información, ubicuidad, visibilidad, calidad de contenidos, etc. Este estudio, por tanto, es complementario a otros muchos ya existentes y otros que habrán de realizarse en el futuro.

Observamos que existen ciertas diferencias entre universidades públicas y privadas:

- Las universidades públicas tienden a olvidar algunas ayudas importantes como mostrar la dirección postal y el teléfono. Las privadas, en cambio, no suelen descuidar el incluir esa información de contacto en la página, tal vez porque con más conscientes de la importancia de permitir a los usuarios el contacto con la universidad de un modo claro e inmediato en orden a facilitar la posibilidad de que esos usuarios se conviertan en alumnos.

- Sólo las universidades públicas tienden a construir sitios fragmentados (una web para cada unidad) como síntoma del alto grado de autonomía de ciertas unidades o secciones de la universidad o bien de la ausencia de políticas de comunicación coordinadas o de una imagen corporativa clara y consolidada.

- Las universidades privadas son más reticentes a ceder su protagonismo y visibilidad en Internet a terceros como Universia, mientras que la inmensa mayoría de las universidades públicas, en virtud de sus acuerdos con Universia, no dudan en favorecer la visibilidad de ésta en detrimento de la suya propia. 
En definitiva, las universidades privadas cuidan más algunos detalles que podrían influir en la pérdida de clientes: ofrecen un contacto claro, imagen cuidada y uniforme, aunque también más personalista (“saludo del rector”). Tras la revisión de estos indicadores en las universidades nos preocupa que:

- La gran mayoría de universidades públicas no sigue un diseño ni mantiene una imagen homogéneos.

- Las universidades (sobre todo las públicas) propician el aumento de PageRank de Universia en detrimento del propio.

- Las páginas ocupan demasiado espacio (peso) y cargan demasiado lento. No todos los usuarios poseen conexiones rápidas. Para los usuarios con conexiones lentas es muy problemático descargarse páginas de inicio de en torno a los 500 $\mathrm{kb}$.

- No se gestionan bien los enlaces de hipertexto.

- Pese a su progresiva implantación, aún no se ha generalizado la utilización de RSS.

- Aún hay universidades que olvidan que han de poseer vocación de servicio y crean páginas con pretensiones de espectacularidad que actúan en detrimento de la correcta comunicación y transmisión de información al usuario.

Por otro lado, resulta esperanzador comprobar que:

- Prácticamente se ha erradicado el abusar del lenguaje administrativo

- Casi ninguna universidad usa ya ventanas emergentes

- Son muy pocas las universidades que aún organizan sus contenidos en base a su organigrama jerárquico en lugar de obedeciendo a criterios de arquitectura de información y vocación de servicio, disminuyendo drásticamente también la presencia de información irrelevante en las páginas de inicio.

- Disminuye, aunque no todo lo que sería deseable, la utilización de menús desplegables, al tiempo que mejora ligeramente la presencia y correcta utilización de buscadores en las páginas de inicio.

La reducción en casi un 10\% de errores en los últimos años no debería hacernos llamar excesivamente rápido al optimismo. Aún se sitúa en torno al $28 \%$ el porcentaje de errores detectados respecto a los 26 indicadores aquí manejados, insuficientes pero seguramente ilustrativos de la situación actual en el diseño de páginas web universitarias en España.

\section{Bibliografía}

Alt64 (2005). Estudio Eyetrack Medios España. Análisis del comportamiento visual de los internautas y la efectividad de la publicidad online. (2005). < http://www.alt64.com/extras/Eyetracking_Media_Espana.pdf $>$ Consuta: 20 septiembre 2009.

disc@pnet (2004) Observatorio para la infoaccesibilidad. La accesibilidad en los portales universitarios: evaluación técnica de la accesibilidad y valoración de la experiencia de usuario en 15 portales de universidades españolas. Madrid: discapnet.com, Fundación ONCE, 2004. <http://www.discapnet.es/inc/infoaccesibilidad/html/Portales_universitarios_sintética.ht m> Consulta: 24 septiembre 2009

disc@pnet (2006). Accesibilidad de Portales Web Universitarios, febrero de 2006. Madrid: discapnet.com, Fundación 2006. 
$<\underline{\text { http://www.discapnet.es/Discapnet/Castellano/Observatorio_infoaccesibilidad/Accesib }}$ ilidad+de+Portales+Web+Universitarios+2006.htm> Consulta: 24 septiembre 2009.

García Gómez, Juan Carlos (2005). Columnas, anchos de línea y legibilidad. // Alzado.org. (2005) < http://www.alzado.org/articulo.php?id_art=462 > Consulta : 26 septiembre 2009

González, M. Paula et. al. (2008). Testing Website Usability in Spanish-Speaking Academia through Heuristic Evaluation and Cognitive Walkthroughs // Journal of Universal Computer Science, vol. 14, no. 9 (2008), 1513-1528 < http://www.jucs.org/jucs_14_9/testing_website_usability_in/jucs_14_09_1513_1528_g onzalez.pdf $>$ (Consulta: 05 noviembre 2009)

Heilmann, C. (2006). Seven Accessibility Mistakes (Part 2). // Digital Web Magazine. (2006). < http://www.digital-web.com/articles/seven_accessibility_mistakes_part_2/ > Consulta : 22 septiembre 2009.

Martínez Méndez, F. Javier (2008). Análisis y medida de la ubicuidad y usabilidad de los portales web de las Universidades Españolas // Scire. 14 : 2 (jul.-dic. 2008) 87-106. http://ibersid.eu/ojs/index.php/scire/editor/submissionReview/1537

Nielsen, J. y Marie Tahir (2002). Usabilidad de páginas de inicio: análisis de 50 sitios web. Madrid [etc.]: Pearson, 2002

Nielsen, J. y Morkes, J. (1997). Concise, SCANNABLE, and Objective: How to Write for the Web. < http://www.useit.com/papers/webwriting/writing.html > Consulta: 15 septiembre 2009.

Nielsen, Jakob (2000). Usabilidad. Diseño de sitios Web. Madrid, etc. : Prentice Hall, 2000

Nielsen, Jakob (2000b). Drop-Down Menus: Use Sparingly. // Alertbox, 2000. < http://www.useit.com/alertbox/20001112.html > Consulta : 25 septiembre 2009

Nielsen, Jakob (2004). Mastery, Mystery, and Misery: The Ideologies of Web Design. // Alertbox, August 30, (2004). < http://www.useit.com/alertbox/20040830.html > Consulta : 25 septiembre 2009

Nielsen, Jakob y Loranger, H. (2006). Prioritizing Web Usability. Berkeley : Pearson, 2006.

Price, J. y Price, L. (2002). Texto vivo. Escribir para la web. Madrid : Pearson, 2002. 